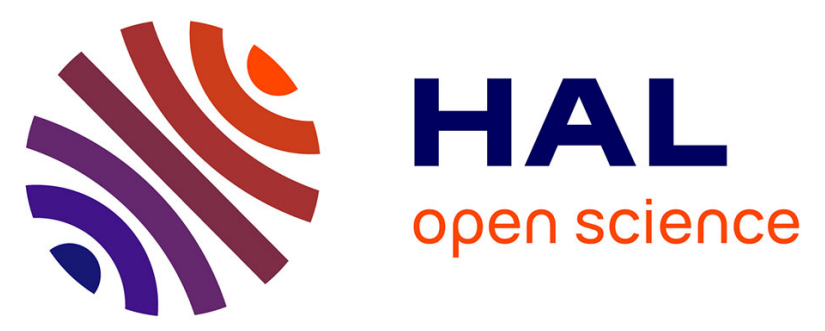

\title{
Do patients with cystic fibrosis participating in clinical trials demonstrate placebo response? A meta-analysis
}

Julie Coton, Ha-Hai Le, Victor Veuillet, Perrine Janiaud, Michel Cucherat, Behrouz Kassai-Koupai, François Gueyffier, Philippe Reix

\section{To cite this version:}

Julie Coton, Ha-Hai Le, Victor Veuillet, Perrine Janiaud, Michel Cucherat, et al.. Do patients with cystic fibrosis participating in clinical trials demonstrate placebo response? A meta-analysis. Journal of Cystic Fibrosis, 2019, 10.1016/j.jcf.2019.02.003 hal-02112948

\section{HAL Id: hal-02112948 \\ https://hcl.hal.science/hal-02112948}

Submitted on 25 Oct 2021

HAL is a multi-disciplinary open access archive for the deposit and dissemination of scientific research documents, whether they are published or not. The documents may come from teaching and research institutions in France or abroad, or from public or private research centers.
L'archive ouverte pluridisciplinaire HAL, est destinée au dépôt et à la diffusion de documents scientifiques de niveau recherche, publiés ou non, émanant des établissements d'enseignement et de recherche français ou étrangers, des laboratoires publics ou privés.

\section{(ㅇ)(1) $\$$}

Distributed under a Creative Commons Attribution - NonCommerciall 4.0 International 


\section{DO PATIENTS WITH CYSTIC FIBROSIS PARTICIPATING IN CLINICAL}

\section{TRIALS DEMONSTRATE PLACEBO RESPONSE? A META-ANALYSIS?}

3 Julie Coton ${ }^{\mathrm{a}, \mathrm{b}}$, Ha-Hai Le ${ }^{\mathrm{a}}$, Victor Veuillet ${ }^{\mathrm{a}}$, Perrine Janiaud ${ }^{\mathrm{c}}$, Michel Cucherat ${ }^{\mathrm{d}}$, Behrouz 4 Kassai-Koupai ${ }^{\mathrm{a}, \mathrm{e}}$, François Gueyffier ${ }^{\mathrm{a}, \mathrm{e}}$ Philippe Reix ${ }^{\mathrm{a}, \mathrm{b}}$.

6 a UMR 5558 CNRS, Equipe EMET. Université Claude Bernard Lyon 1, Lyon France

$7{ }^{\mathrm{b}}$ Centre de ressources et de compétences de la mucoviscidose, Hospices Civils de Lyon, 8 Lyon, France.

$9{ }^{\mathrm{c}}$ Meta-Research Innovation Center at Stanford (METRICS), Stanford University, Stanford, 10 California.

11 d Department of Clinical Pharmacology, Université Claude Bernard Lyon 1, Lyon, France.

$12{ }^{\mathrm{e}}$ EPICIME-Clinical Investigation Center, INSERM CIC1407/UMR5558, Bron, France

14 Running head title: Placebo response in cystic fibrosis

15 Keywords: randomized, clinical trials, placebo response, cystic fibrosis, meta-analysis

16 Abstract/Manuscript word counts: 208/3160 (ref excluded)

17 Tables: 1

18 Figures: 4

19 Supplemental materials: 1 table and 1 figure

This research did not receive any specific grant from funding agencies in the public, 22 commercial or not-for-profit sectors

\section{Corresponding author:}

Philippe Reix, Centre de ressources et de compétence pour la Mucoviscidose 59 Boulevard Pinel. 69677 BRON CEDEX

E-mail: philippe.reix@chu-lyon.fr

Phone: +331 (4) 57855470

$31 \quad$ Fax: $+331(4) 57626768$ 


\section{ABSTRACT}

2 Background. Patients' and families' expectation that a cure for cystic fibrosis (CF) will be

3 found is high. In other debilitating conditions, high expectation has been shown to drive a

4 strong placebo response (PR). Therefore, our goal was to evaluate PR on objective continuous

5 outcomes $\left(\mathrm{FEV}_{1}, \mathrm{BMI}\right)$ and the CF Questionnaire Revised-Respiratory Domain (CFQR-RD)

6 monitored during randomised clinical trials (RCTs) for CF. Methods. We conducted a meta-

7 analysis after a systematic review of the literature carried out to identify RCTs with FEV ,

8 CFQR-RD and BMI as outcome measures. The standardised mean difference (SMD) was

9 calculated to estimate the PR. A meta-regression analysis was conducted to assess other

10 contributing factors on PR such as study design, trial duration, patient age and disease

11 severity. Results. Out of 289 RCTs found in the search, we identified 61 articles (published

12 from 1987 to 2017) with respectively 59, 17 and 9 reporting $\mathrm{FEV}_{1}, \mathrm{CFQR}-\mathrm{RD}$ and BMI at the

13 start and at the end of the RCTs. No significant PR was found on FEV 1 or CFQR-RD.

14 However, a small but significant PR was found on BMI (SMD, 0.09 (95\% CI (0.01; 0.17);

$15 \mathrm{p}=0.03)$. Conclusion. The PR seems higher when measuring BMI. However, it is not clear

16 whether this improvement can be explained by a PR alone

17

18 


\section{ABBREVIATIONS}

2

3 BMI: body mass index

4 CI: confidence interval

5 CF: cystic fibrosis

6 CFTR: cystic fibrosis conductance transmembrane regulator

7 CFQR-RD: Cystic-Fibrosis Questionnaire Revised-Respiratory Domain

$8 \quad$ FEV $_{1}$ : forced expiratory volume in one second

9 FVC: functional vital capacity

10 HRQOL: health-related quality of life

11 PPE: perceived placebo effect

12 PR: placebo response

13 RCTs: randomised controlled trials

14 REML: restricted maximum likelihood estimator

15 


\section{Introduction}

2 Because of the progressive and lethal nature of the disease, patients with CF and their families

3 have high expectations that a cure will be found (1). In diverse medical disorders ranging

4 from Alzheimer disease to asthma, high expectation has been shown to drive a strong placebo

5 response (PR) (2).

6 The true placebo effect is known as "any effects attributable to a pill, potion or procedure but 7 not to its pharmacodynamics or specific properties" (3), with possible benefit and 8 improvement of symptoms. While some evidence illustrates that a true placebo effect is 9 biologically modulated by neurotransmitters $(2,4)$ associated with specific brain structures 10 (4), its psychological contributors could be explained by both conscious and subconscious 11 mechanisms $(5,6)$.

12 Since 1955 with Beecher's statement on the "true" placebo effect, this term has regularly been 13 misinterpreted and confounded with the "perceived placebo effect" or the "placebo response"

14 (7). The PR, the term we will use in this article to avoid any confusion with the placebo effect, 15 equals the "true" placebo effect (8) plus other factors that may explain the improvement or 16 worsening of the patients' outcomes in the placebo arm of clinical trials. This includes (1) the 17 disease's natural history and its possible spontaneous regression (i.e. regression to the mean or 18 intra-subject variability), (2) concomitant treatments, (3) experimental subordination (the 19 subject learns the expected effects and thus tells the expected response) and (4) conditioned 20 responses (5).

21 In $\mathrm{CF}$, patients and family's expectations may interfere with the PR on several of the above 22 listed factors. However, a systematic evaluation of PR in CF has never been addressed $(9,10)$.

23 This may be of importance for clinicians to better determine the "true" magnitude of the 24 clinical benefit they may expect for their patients. This may also be important for CF 
1 researchers for methodological purposes (power calculation, study design, outcome measure

2 selection).

3 The aim of this study was therefore to determine the PR based on three continuous outcomes

4 considered as particularly relevant in CF: respiratory function measured with forced

5 expiratory volume in one second $\left(\mathrm{FEV}_{1}\right)$, quality of life with the respiratory domain of the

6 Cystic-Fibrosis Questionnaire Revised (CFQR-RD) and nutritional status with body mass

7 index (BMI).

\section{Material and methods}

\subsection{Literature search}

10 We performed a literature search using PubMed (US National Library of Medicine, Bethesda,

11 MD, USA) and the Cochrane Library (John Wiley and Sons, Chichester, UK) focusing on 12 placebo-controlled RCTs in patients with CF. The last bibliographic search was done on 13 December $12^{\text {th }}, 2018$. We used the following terms: "placebo AND cystic fibrosis AND 14 randomised controlled trial" as well as "cystic fibrosis AND placebo" and filtered the type of 15 study ("clinical trial" for PubMed and "trial" for the Cochrane Library).

\subsection{Selection of meta-analyses}

17 Criteria for inclusion were randomised double-blind placebo-controlled trials in patients with $\mathrm{CF}$ of any age and without a lower limit for the date of publication. The age limit between

19 adults and children was set at 18 years old. Eligible interventions were all pharmacological 20 treatments excluding homeopathic treatments, specific diets and vitamin supplementation.

21 Our research was restricted to studies published in English or French. 


\subsection{Data extraction}

2 For each study included, the following information was extracted and entered in the database:

3 (1) date of publication, (2) design of the study (randomisation, blinding, parallel group or 4 cross-over), (3) duration of the study, (4) patients' characteristics (adults, children or both;

5 sex, age, number of patients included in placebo and treatment arms), (5) the drug assessed

6 and its therapeutic class, (6) drug doses, (7) change from baseline to the end of the study for

7 three continuous outcomes in the placebo and treatment arms: $\mathrm{FEV}_{1}, \mathrm{BMI}$, health-related

8 quality of life outcomes with the respiratory domain of the CF questionnaire revised (CFQR-

9 RD), (8) percentage of exacerbations during the study for each arm when available, (9) CF

10 lung disease severity based on baseline $\mathrm{FEV}_{1}$ value when available, (10) CFTR gene

11 mutations if given, (11) any adverse event in both arms if available as well as withdrawals for

12 any adverse event and (12) concomitant treatments.

13 Data were extracted independently by two authors (JC and VV) and then compared.

14 Inconsistencies were resolved by consensus.

\subsection{RCT quality assessment}

The quality of the RCTs was estimated with the Cochrane assessment risk of bias (15) and the

17 five-point scoring instrument developed by Jadad and Enkin (11-13).

\subsection{Type of pharmacological interventions}

19 We classified pharmacological interventions during RCTs into one of the five drug categories 20 (the first three being the most frequently explored in RCTs in CF): pulmonary (P), nutrition $21(\mathrm{~N})$, microbiology/anti-infective $(\mathrm{M})$, basic defect $(\mathrm{BD})$ and other $(\mathrm{O})$.

\subsection{Outcome measures}

23 We extracted the change from the start (participant characteristics at study entry) to the end of 24 the trial (even if it did not correspond to the time point evaluation of the study's primary 
1 endpoint) for the three continuous outcomes most commonly used in CF RCTs: FEV 1 , BMI

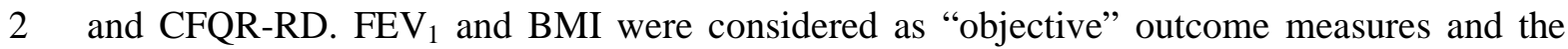

3 CFQR-RD as a continuous "subjective" outcome measure.

\subsection{Dealing with missing data}

5 Since we considered continuous outcomes, when the standard deviation (SD) was missing, we

6 estimated it from the standard error (SE) or confidence interval (CI) (14).

\subsection{Statistical analysis}

8 The PR was defined as the difference in the outcome measured in the patients of the placebo

9 arm between baseline and the "end-of-study" time points. To anticipate heterogeneity in the continuous data reporting ( $\mathrm{FEV}_{1}, \mathrm{BMI}$ and $\left.\mathrm{CFQR}-\mathrm{RD}\right)$, we calculated the standardised mean difference (SMD) for each outcome instead of the MD. A positive SMD value indicates an improvement under placebo and inversely for a negative SMD value.

Since heterogeneity was expected, a meta-analytic random effects model (inverse variance method) was used, rather than a fixed-effects model (15). The heterogeneity of the SMD across the studies was assessed using the $\mathrm{I}^{2}$ statistical test (which can be interpreted as the proportion of the observed discrepancy in the estimation of the effect, within a group of trials,

17 which cannot be accounted for by random variation) (16). Publication bias was assessed by a 18 visual funnel plot.

We conducted a univariate restricted maximum likelihood estimator (REML) meta-regression analysis to assess potential contributors to the PR (17). The following explanatory variables were defined beforehand: (1) type of treatment (dummy variables created, pharmacological 22 intervention of interest coded as 1 and others coded as 0); (2) year of publication; (3) disease severity (dummy variables created); (4) age; (5) population (adults versus children); (6) trial duration; (7) design of the study (cross-over design coded 0 and parallel design coded 1). A 
1 QE-test was performed to assess residual heterogeneity when moderators were included. QM

2 was the statistical test for omnibus test coefficients. The coefficients were expressed using the

$3 \quad \beta$ letter. All analyses were performed with R (R-studio Inc; Version 3.4.4; https://www.r4 project.org/).

\section{3. Results}

\subsection{Description of studies}

7 We identified 1417 reviews. After screening the titles and abstracts, and the exclusion of

8 irrelevant and duplicate studies, 250 reviews were screened (Figure 1). Sixty-one RCTs (from

91987 to 2017) were finally analysed (Table S1 supplemental material). Respectively 59, 17

10 and 9 RCTs reported results for $\mathrm{FEV}_{1}, \mathrm{CFQR}-\mathrm{RD}$ and BMI.

11 There were 58 trials with a parallel design and three with a cross-over design. When the

12 literature search was conducted, there were 29, 14, 12, 3 and 3 RCTs categorised into the 13 pulmonary, microbiology/anti-infective, basic defect, nutrition and "other" categories, 14 respectively. There was a low risk of bias (Cochrane assessment: 1 and Jadad score between 4 15 and 5) for 29 RCTs (47.5\%). It remained undetermined for the others (Cochrane assessment: $162)$.

17 Concomitant treatments were specified in 46 RCTs (75.4\%). Adverse effects (of any type) were reported in 32 studies $(52.5 \%)$ with no significant difference between the placebo and

19 treatment arms $(\mathrm{p}>0.05)$. Placebo arms contained 4648 patients (2242 males) and the 20 treatment arms included 4917 patients (53.9\% males). The mean age in the placebo arm was 2119.3 (range, 2.3-32.7) years. The mean trial duration was 207.8 days. 
2 PR SMD was estimated at -0.16 in a random effect model $(95 \%$ CI $(-0.24 ;-0.08) ; p<0.000$

3 1) (Figure 2), indicating a trend toward deterioration of $\mathrm{FEV}_{1}$ in the placebo group. A signific

4 ant heterogeneity across studies was identified $\left(\mathrm{I}^{2}=81.9 \%, \mathrm{Q}(\mathrm{df}=58)=319.16, \mathrm{p}<0.0001\right)$.

5 The funnel plot was not asymmetrical (Figure S1-A; $\underline{\text { supplemental material). }}$

6 Univariate meta-regression was then performed to assess the influence of disease or study-

7 related factors on $\mathrm{PR}$ assessed on $\mathrm{FEV}_{1}$ (Table 1). Year of publication did not affect $\mathrm{FEV}_{1}$ in

8 the placebo group $(\mathrm{QM}(\mathrm{df}=1)=2.58, \beta=0.01, \mathrm{p}=0.1)$, nor did age of the participants at

9 inclusion $(\mathrm{QM}(\mathrm{df}=1)=0.23, \beta=-0.003, \mathrm{p}=0.63)$. The $\mathrm{PR}$ on $\mathrm{FEV}_{1}$ did not differ between

10 adults and children $(\mathrm{QM}(\mathrm{df}=1)=0.23 ; \mathrm{p}=0.63)$, nor did trial duration $(\mathrm{QM}(\mathrm{df}=1)=0.02$,

$11 \beta=0 \mathrm{p}=0.88)$ as well as the type of the intervention $(\mathrm{QM}(\mathrm{df}=4)=1.63, \mathrm{p}=0.80)$ influence

12 PR. Given that the number of studies varied between parallel group $(\mathrm{n}=56)$ and cross-over

13 studies $(\mathrm{n}=3)$, it was not possible to evaluate the influence of study design on PR on $\mathrm{FEV}_{1}$.

14 Finally, patients' $\mathrm{FEV}_{1}$ baseline value did not influence PR $(\mathrm{QM}(\mathrm{df}=2)=2.68, \mathrm{p}=0.26)$.

\subsection{PR evaluated on CFQ-RD}

The overall SMD for CFQR-RD was estimated at $-0.11(95 \%$ CI $(-0.34 ; 0.11) ; \mathrm{p}=0.32)$ (Fig

ure 3). Wide heterogeneity across studies was found $\left(\mathrm{I}^{2}=93.6 \%, \mathrm{p}<0.0001\right)$. The funnel plot was not asymmetrical (Figure S1-B, supplemental material).

Using univariate meta-regression (Table 1), a greater PR was observed on CFQR in older pati ents $(\mathrm{QM}(\mathrm{df}=1)=16.9, \beta=0.04, \mathrm{p}$-value $<0.0001)$ with one outlier which appeared to driv e the effect. Once removed, the effect of age was no longer significant $(\mathrm{QM}(\mathrm{df}=1)=0.97, \beta$ $=-0.009, \mathrm{p}$-value $=0.32)$. PR assessed on CFQR did not differ between adults and children $(($ $\mathrm{QM}(\mathrm{df}=1)=0.89, \mathrm{p}=0.34)$. Year of publication $(\mathrm{QM}(\mathrm{df}=1)=0.007, \beta=0.003, \mathrm{p}=0.93)$ the type of intervention $(\mathrm{QM}(\mathrm{df}=2)=1.13$, p-value $=0.57)$, patients' baseline $\mathrm{FEV}_{1}(\mathrm{QM}(\mathrm{d}$ $\mathrm{f}=2)=2.76$, $\mathrm{p}$-value $=0.25)$ did not influence PR assessed on CFQR. Trial duration was fou 
1 nd to influence PR assessed on CFQR as well $(\mathrm{QM}(\mathrm{df}=1)=79.7, \beta=-0.002$, p-value $<0.00$

2 01). The longer the trial duration, the more the CFQR-RD deteriorated in the placebo group.

3 As observed with age, an outlier drives this effect, since after removal the result was no longe

$4 \mathrm{r}$ significant $(\mathrm{QM}(\mathrm{df}=1)=0.80, \beta=0.0006, \mathrm{p}$-value $=0.37$. Finally, assessing study design

5 on PR using the CFQR-RD was not possible given the low number of trials in each group.

The SMD assessed on BMI was estimated at 0.09 in a random effect model (95\% CI (0.01;

0.17); $\mathrm{p}=0.03$ ), indicating a trend toward improvement of BMI in the placebo group (Figure

4).

The funnel plot was not asymmetrical (Figure S1-C supplemental material). Because of the

11 small number of RCTs reporting BMI, we were unable to perform meta-regression to explore

12 the contribution of other factors such as age at inclusion, study design or the type of

13 intervention. Moreover, we were unable to analyse data form children and adults apart,

14 because BMI results were not given separately.

\section{DISCUSSION}

16

To our knowledge, this is the first meta-analysis to assess PR in patients with CF investigated in RCTs. The research question behind this work may have implications on the interpretation of the therapeutic effect of past, ongoing and future RCTs for both clinicians and CF researchers.

PR is the combination of the true placebo effect and other factors that may alter the response measured on certain outcomes in patients under the placebo arm of a RCT (18). In a metaanalysis we recently showed that PR was not found to be stronger in children than in adults (19). In the present study, no PR difference was found in patients with CF when assessing 
1 continuous outcomes such as $\mathrm{FEV}_{1}$ and CFQR-RD. However, a weak but statistically

2 significant PR was found on BMI.

3 We conducted this meta-analysis on PR by choosing outcomes that were commonly reported 4 and the most relevant regarding CF. CFQR-RD, $\mathrm{FEV}_{1}$ and $\mathrm{BMI}$ are three continuous variables 5 largely used in RCTs and the two latter outcomes in CF clinics. They explore the three most 6 important dimensions of CF disease (i.e. CF-related lung disease with $\mathrm{FEV}_{1}$; the patient's 7 quality of life with CFQR-RD and nutritional status with BMI) (20-22). Despite the 8 limitations of both $\mathrm{FEV}_{1}$ and $\mathrm{BMI}$ in properly tracking a therapeutic effect in some patients, 9 particularly the youngest patients whose $\mathrm{FEV}_{1}$ and BMI may be within normal ranges, they 10 remain the outcomes on which clinicians, the FDA and the European Medicine Agency base 11 their decisions to assess the therapeutic effect of an intervention.

12 We found that there was no evidence of a PR in patients with $\mathrm{CF}$ when looking at $\mathrm{FEV}_{1}$ or 13 CFQR-RD. Both tended to deteriorate between the start and the end of the trials. We found 14 that $\mathrm{FEV}_{1}$ decreased in the placebo group during RCTs independently of patient- or trial15 related factors. With the CFQR-RD the deterioration in the placebo group was influenced by 16 the patient's age and the trial duration mainly because of an outlier trial. These results likely 17 reflect both the progressively deteriorating nature of the $\mathrm{CF}$ but also a possible regression to the mean. The genetic origin of the disease and the current standard of care, which mainly 19 treats symptoms, explain that CF remains a slowly progressive medical condition without 20 potential for remission (23). If the deterioration of $\mathrm{FEV}_{1}$ and CFQR-RD had been mainly 21 driven by the disease progression, a "time-dependent" deterioration would have been found. 22 This was not the case, and the meta-regression analysis showed these two outcomes were not impacted by trial duration. We therefore believe that it reflects the regression to the mean of $24 \mathrm{FEV}_{1}$ and CFQR-RD. At the start of the trial, it is likely that patients are selected at their best 25 clinical condition and "regress" to their usual (mean) outcome measures. Regression to the 
1 mean is a well-known factor explaining PR and needs to be considered in order to properly

2 interpret the results observed in placebo arms (18).

3 However, a small (SMD 0.09; 95\% CI 0.01-0.17) but statistically significant PR was detected 4 on BMI. By comparison, but in a very different pathological condition, a PR was observed in 5 young patients with intellectual deficiency with a SMD of 0.468 (SE: 0.150; p = 0.002) (24).

6 Patients with $\mathrm{CF}$ are more at risk of stunted growth with low BMI. Our results seem to 7 indicate that patients with $\mathrm{CF}$ tended to improve their BMI (i.e. nutritional status) in the 8 placebo group during RCTs. It is not clear whether this improvement can be explained by a 9 PR alone. There are several other reasons explaining that patients improve their BMI during 10 RCTs. Firstly, a 0.09 standardised mean difference on BMI between the two arms of an RCT 11 indicates a very small absolute change in weight between the two groups of patients. 12 Secondly, the improvement of BMI in the placebo group may also reflect (1) the the natural 13 increases of BMI with age (especially among children) (25), (2) regression to the mean (as 14 discussed above) or the impact of other factors known to be part of the PR such as (3) 15 conscious expectancy (the subject learns the expected effects and alters his/her eating 16 behaviour) or (4) conditioned responses or associative learning (26). Retrospectively, it was 17 not possible to distil out true placebo effect from these other factors. Because of the low 18 number of trials included in the meta-regression analysis, we were also unable to explore a 19 number of important contributing factors, particularly age at study entry and the class of the 20 investigational drug tested. Regarding age, several groups have reported that the PR was more 21 pronounced in children suffering neurological or neurodevelopmental conditions $(24,27)$, 22 probably through a placebo-by-proxy process $(28,29)$. However, it seems from our group that 23 the magnitude of the PR of children is essentially based on disease, age, study design and the 24 outcome studied (19). 
1 Improving our knowledge on placebo responses in patients with $\mathrm{CF}$ may have pragmatic

2 implications for both clinicians and CF trialists: for clinicians, when looking at the results of

3 RCTs and in the perspective of using the tested drug in their patients, to better determine the

4 magnitude of the therapeutic effect they may expect in real life; for CF researchers, this may

5 be of importance for outcome selection, power calculations and study design when using

6 outcomes potentially submitted to placebo responses. Using a "placebo-run-in-period" during

7 RCTs could be useful but it may overestimate the therapeutic benefit (30).

8 The potential influence of PR on BMI in patients with CF may deserve attention even if BMI

9 is not usually used as a primary endpoint in CF RCTs. For 10 years, the basic defect of CFTR

10 can be partially restored using CFTR potentiators, amplifiers and activators, alone or in

11 combination (31). More than a dozen RCTs using CFTR modulators have been experimented

12 in patients with $\mathrm{CF}$ to date. The results of these RCTs have consistently shown an

13 improvement in patients' BMI while sometimes showing a less convincing functional

14 respiratory benefit when looking at $\mathrm{FEV}_{1}$ changes. The higher "nutritional" benefit can be

15 questioned, and several possible explanations have already been discussed above. Moreover,

16 it is uncertain whether the observed PR for BMI would be consistent across different age

17 groups and how it can be translated in clinic to accurately evaluate clinical benefit.

18 The main strengths of this study are the originality of the research question and the rigorous

19 method of meta-analysis and meta-regression conducted after an exhaustive literature search.

20 There are a number of limitations, however. Firstly, despite being exhaustive, the number of

21 RCTs available for analysis was relatively low despite the high number of RCTs conducted in

22 patients with CF to date. Indeed, a significant number of RCTs (65 RCTs with missing data at

23 the start and/or at the end of the study and an additional 63 RCTs that reported data as

24 abstracts only) could not be included in the final analysis. Secondly, other respiratory

25 outcome such as pulmonary exacerbation, which is an important patient-related outcome 
1 measure, should be explored because $\mathrm{FEV}_{1}$ alone does not capture the entire spectrum of $\mathrm{CF}$

2 lung disease. Unfortunately, this analysis was not possible because there were no data

3 available at baseline, making the evaluation of the PR between the start and the end 4 impossible.

5 In conclusion, this work indicates that patients undergoing RCTs may be submitted to a small

6 but significant PR on BMI. It is not clear whether this improvement can be explained by a PR

7 alone. This study emphasizes the importance of having appropriate control groups in clinical 8 trials. 


\section{REFERENCES}

1. Schlangen M, Reimann AL. Medical needs of cystic fibrosis patients and policies for fair co-operation between small and middle-sized companies and patient organizations. J Cyst Fibros. 2011;10 Suppl 2:S110-3.

2. Finniss DG, Kaptchuk TJ, Miller F, Benedetti F. Biological, clinical, and ethical advances of placebo effects. Lancet. 2010;375(9715):686-95.

3. Wolf S. The pharmacology of placebos. Pharmacol Rev. 1959;11:689-704.

4. Meissner K, Bingel U, Colloca L, Wager TD, Watson A, Flaten MA. The placebo effect: advances from different methodological approaches. J Neurosci. 2011;31(45):1611724.

5. Ernst E. Placebo: new insights into an old enigma. Drug Discov Today. 2007;12(9$10): 413-8$.

6. Benedetti F. Mechanisms of placebo and placebo-related effects across diseases and treatments. Annu Rev Pharmacol Toxicol. 2008;48:33-60.

7. Eigen H, Rosenstein BJ, FitzSimmons S, Schidlow DV. A multicenter study of alternate-day prednisone therapy in patients with cystic fibrosis. Cystic Fibrosis Foundation Prednisone Trial Group. J Pediatr. 1995;126(4):515-23.

8. Gotzsche PC. Is there logic in the placebo? Lancet. 1994;344(8927):925-6.

9. Dutile S, Kaptchuk TJ, Wechsler ME. The placebo effect in asthma. Curr Allergy Asthma Rep. 2014;14(8):456.

10. Wechsler ME, Kelley JM, Boyd IO, Dutile S, Marigowda G, Kirsch I, et al. Active albuterol or placebo, sham acupuncture, or no intervention in asthma. N Engl J Med. 2011;365(2):119-26.

11. Moher D, Jadad AR, Nichol G, Penman M, Tugwell P, Walsh S. Assessing the quality of randomized controlled trials: an annotated bibliography of scales and checklists. Control Clin Trials. 1995;16(1):62-73.

12. Moher D, Pham B, Jones A, Cook DJ, Jadad AR, Moher M, et al. Does quality of reports of randomised trials affect estimates of intervention efficacy reported in metaanalyses? Lancet. 1998;352(9128):609-13.

13. Jadad AR, Cook DJ, Jones A, Klassen TP, Tugwell P, Moher M, et al. Methodology and reports of systematic reviews and meta-analyses: a comparison of Cochrane reviews with articles published in paper-based journals. JAMA. 1998;280(3):278-80.

14. Higgins JPT, Green S. Cochrane Handbook for Systematic Reviews of Interventions. 5.1.0 (updated March 2011). The Cochrane Collaboration, 2011; 2011 [Available from: http://handbook.cochrane.org/.

15. Brockwell SE, Gordon IR. A comparison of statistical methods for meta-analysis. Stat Med. 2001;20(6):825-40.

16. Higgins JP, Thompson SG. Quantifying heterogeneity in a meta-analysis. Stat Med. 2002;21(11):1539-58.

17. Baker WL, White CM, Cappelleri JC, Kluger J, Coleman CI, Health Outcomes P, et al. Understanding heterogeneity in meta-analysis: the role of meta-regression. Int J Clin Pract. 2009;63(10):1426-34.

18. Ernst E, Resch KL. Concept of true and perceived placebo effects. BMJ. 1995;311(7004):551-3.

19. Janiaud P, Cornu C, Lajoinie A, Djemli A, Cucherat M, Kassai B. Is the perceived placebo effect comparable between adults and children? A meta-regression analysis. Pediatr Res. 2017;81(1-1):11-7. 
20. Quittner AL, Buu A, Messer MA, Modi AC, Watrous M. Development and validation of The Cystic Fibrosis Questionnaire in the United States: a health-related quality-of-life measure for cystic fibrosis. Chest. 2005;128(4):2347-54.

21. Bodewes FA, Verkade HJ, Taminiau JA, Borowitz D, Wilschanski M, Working group Cystic F, et al. Cystic fibrosis and the role of gastrointestinal outcome measures in the new era of therapeutic CFTR modulation. J Cyst Fibros. 2015;14(2):169-77.

22. VanDevanter DR, Konstan MW. Outcome measures for clinical trials assessing treatment of cystic fibrosis lung disease. Clin Investig (Lond). 2012;2(2):163-75.

23. Ratjen F, Bell SC, Rowe SM, Goss CH, Quittner AL, Bush A. Cystic fibrosis. Nat Rev Dis Primers. 2015;1:15010.

24. Curie A, Yang K, Kirsch I, Gollub RL, des Portes V, Kaptchuk TJ, et al. Placebo Responses in Genetically Determined Intellectual Disability: A Meta-Analysis. PLoS One. 2015;10(7):e0133316.

25. Boelle PY, Viviani L, Busson PF, Olesen HV, Ravilly S, Stern M, et al. Reference percentiles for FEV(1) and BMI in European children and adults with cystic fibrosis. Orphanet J Rare Dis. 2012; 7:64.

26. Klinger R, Soost S, Flor H, Worm M. Classical conditioning and expectancy in placebo hypoalgesia: a randomized controlled study in patients with atopic dermatitis and persons with healthy skin. Pain. 2007;128(1-2):31-9.

27. Rheims S, Cucherat M, Arzimanoglou A, Ryvlin P. Greater response to placebo in children than in adults: a systematic review and meta-analysis in drug-resistant partial epilepsy. PLoS Med. 2008;5(8):e166.

28. Grelotti DJ, Kaptchuk TJ. Placebo by proxy. BMJ. 2011;343:d4345.

29. Weimer K, Gulewitsch MD, Schlarb AA, Schwille-Kiuntke J, Klosterhalfen S, Enck P. Placebo effects in children: a review. Pediatr Res. 2013;74(1):96-102.

30. Pablos-Mendez A, Barr RG, Shea S. Run-in periods in randomized trials: implications for the application of results in clinical practice. JAMA. 1998;279(3):222-5.

31. Clancy JP, Cotton CU, Donaldson SH, Solomon GM, VanDevanter DR, Boyle MP, et al. CFTR modulator theratyping: Current status, gaps and future directions. J Cyst Fibros. 2018. 
Figure 1 - Trial flow chart
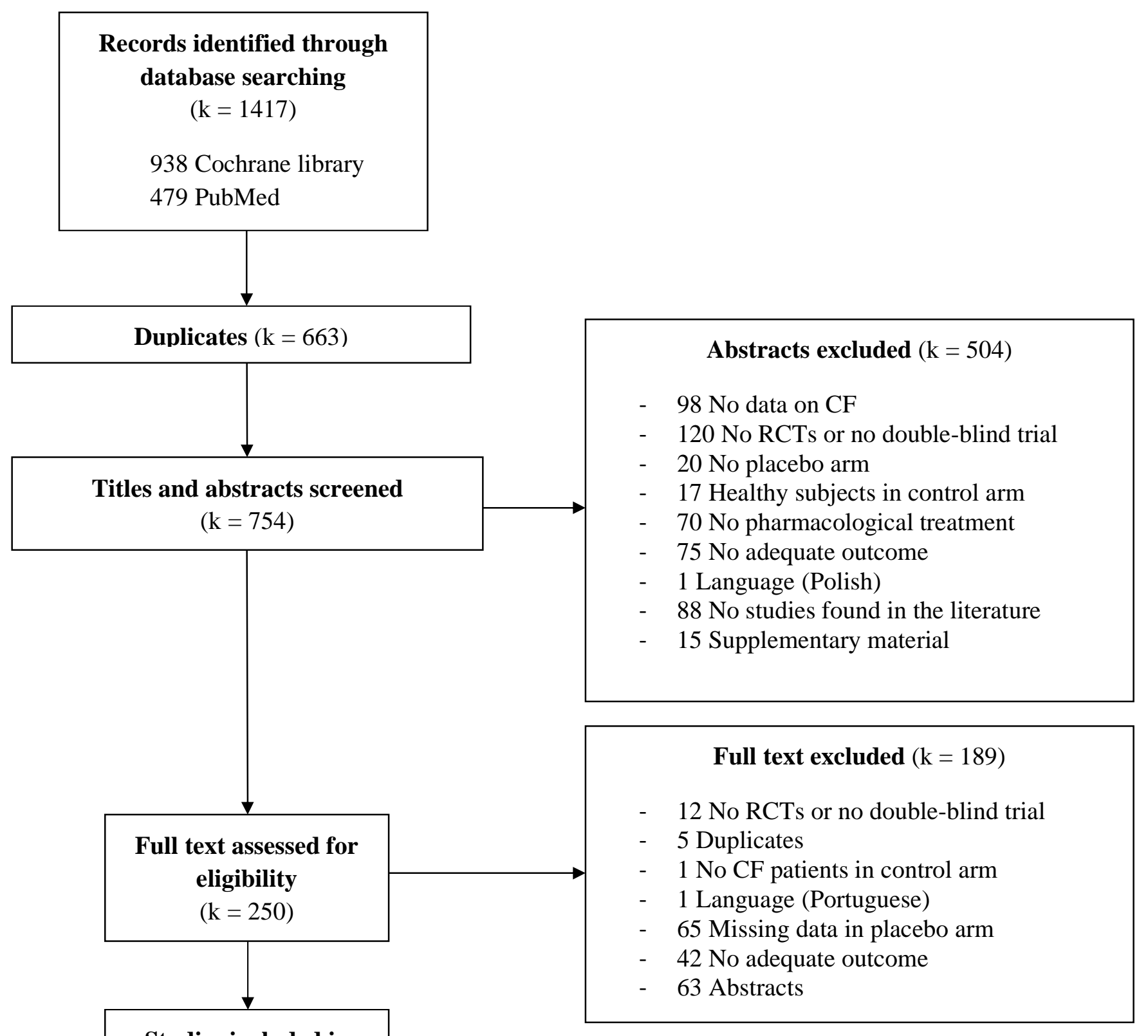

Studies included in qualitative synthesis $(\mathrm{k}=61)$

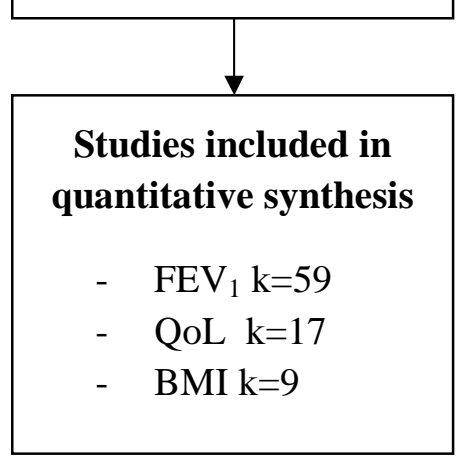


Figure 2 - Forest plot of placebo responses evaluated on $\mathrm{FEV}_{1}$

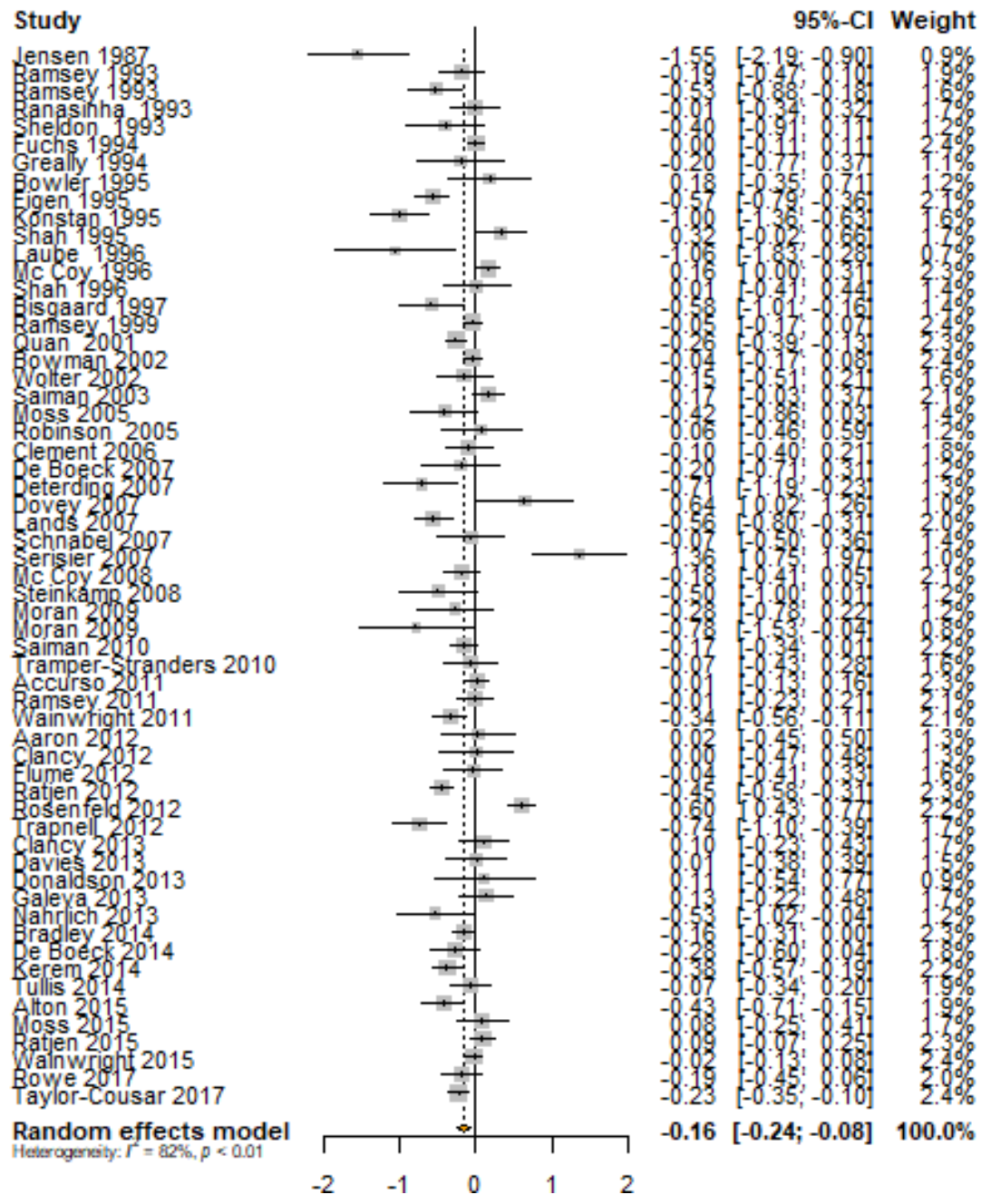

Individual standardised mean differences (SMD) were calculated for each study and are indicated separately on each line. A positive SMD value indicates an improvement under placebo and a negative SMD value a deterioration under placebo. Overall perceived placebo effect SMD was estimated at -0.16 in a random effect model (95\% CI, 0.24; -0.08); $\mathrm{p}=0.0002$, indicating a trend toward deterioration of $\mathrm{FEV}_{1}$ under placebo arm. 


\section{Figure 3 - Forest plot of placebo responses evaluated on CFQR-RD}

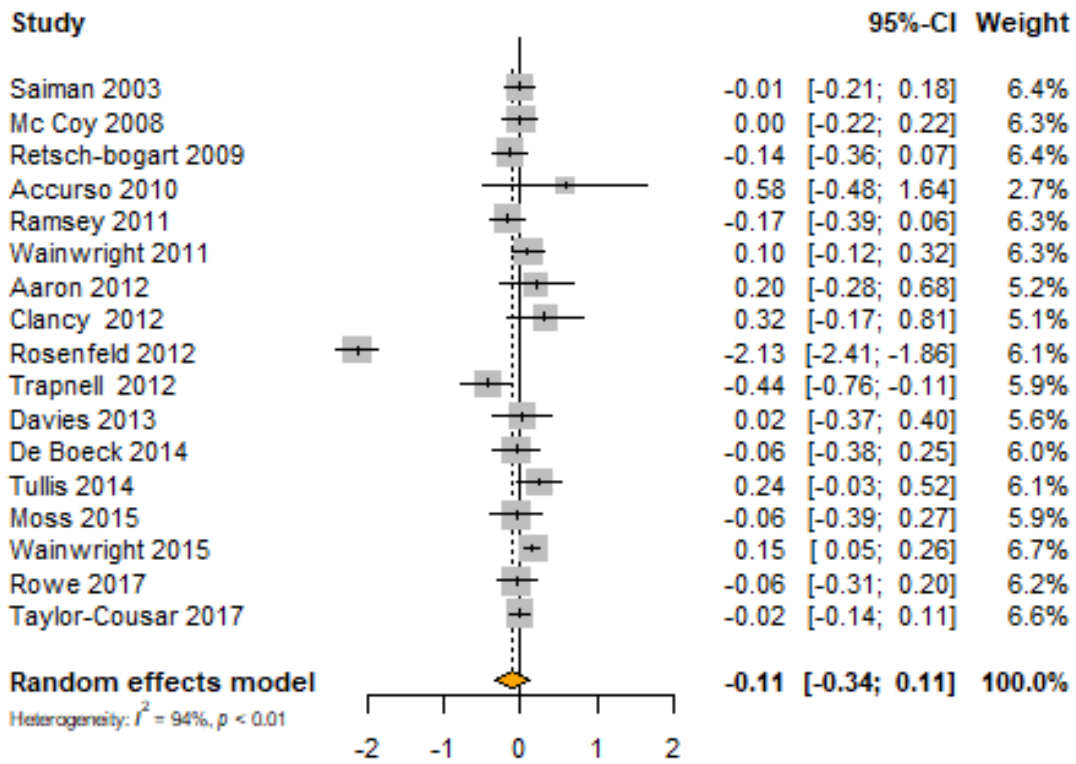

Perceived placebo effect standardised mean difference (SMD) was estimated to -0.11 (95\%

$\mathrm{CI},(-0.34 ; 0.11) ; \mathrm{p}=0.32)$. It was statistically non-significant, indicating an absence of PPE on this outcome measure. 


\section{Figure 4 - Forest plot of placebo responses evaluated on BMI}
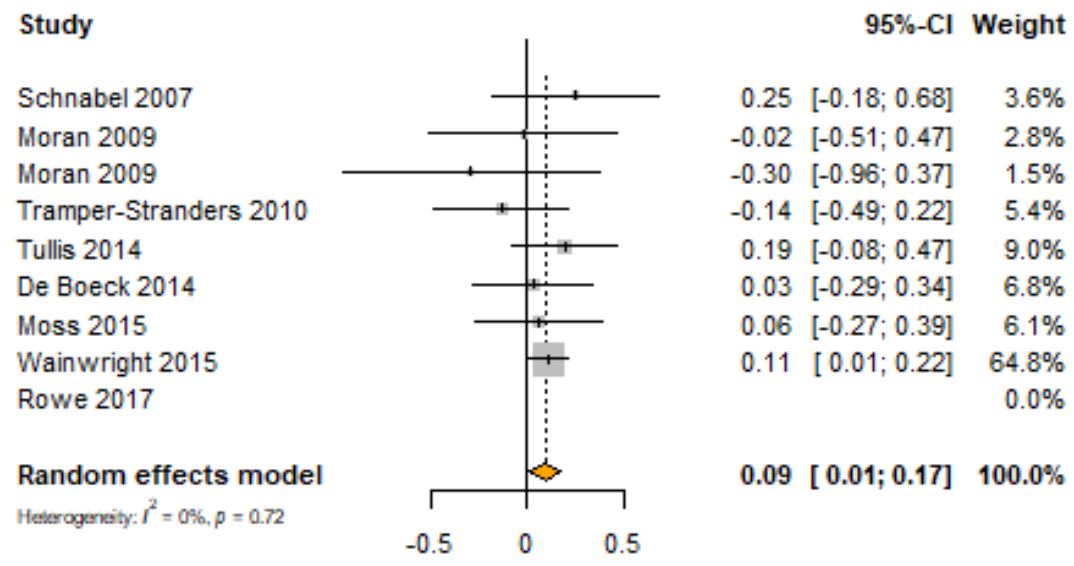

Perceived placebo effect standardised mean difference (SMD) was estimated at 0.09 in a random effects model $(95 \% \mathrm{CI}, 0.01 ; 0.17) ; \mathrm{p}=0.03$, indicating a small but statistically significant improvement of BMI under placebo arm. 
Table 1 Univariate meta-regression of the potential influence of trial- and patientrelated factors on perceived placebo effect assessed through $\mathrm{FEV}_{1}, \mathrm{CFQR-RD}$ and BMI in RCTs conducted in patients with $\mathbf{C F}$

\begin{tabular}{|c|c|c|}
\hline $\begin{array}{l}\text { Variables } \\
\text { ( } k=\text { number of studies) }\end{array}$ & $\begin{array}{l}\text { Categorical data } \\
\text { QM (df) (p-value) }\end{array}$ & $\begin{array}{c}\text { Continuous data } \\
\beta \text { (p-value) }\end{array}$ \\
\hline \multicolumn{3}{|l|}{ FEV $_{1}$} \\
\hline Year of publication $(\mathrm{k}=59)$ & - & $0.01(0.1)$ \\
\hline Trial duration $(\mathrm{k}=59)$ & - & $0(0.88)$ \\
\hline Age $(k=57)$ & - & $-0.003(0.63)$ \\
\hline CF lung disease severity & $2.68(\mathrm{df}=2)(0.26)$ & - \\
\hline Classification of drug & $1.63(\mathrm{df}=4)(0.8)$ & - \\
\hline Trial design & NP & - \\
\hline \multicolumn{3}{|l|}{ CFQR-RD } \\
\hline Year of publication $(\mathrm{k}=17)$ & - & $0.007(0.93)$ \\
\hline Trial duration $(\mathrm{k}=17)$ & - & $-0.002(<0.0001)$ \\
\hline Age $(\mathrm{k}=17)$ & - & $0.04(0.0001)$ \\
\hline $\mathrm{CF}$ lung disease severity & $2.76(\mathrm{df}=2)(0.25)$ & - \\
\hline Classification of drug & $1.13(\mathrm{df}=2)(0.57)$ & - \\
\hline Trial design & $\mathrm{NP}$ & \\
\hline \multicolumn{3}{|l|}{ BMI } \\
\hline & NP & NP \\
\hline
\end{tabular}

Univariate meta-regression analysis was used to evaluate the influence of the above factors on PPE through $\mathrm{FEV}_{1}$ and CFQR-RD: year of publication, trial duration, age, lung disease severity and classification. Trial design could not be integrated into the meta-regression. The meta-regression could not be performed for BMI because the number of available studies was under $10(\mathrm{k}=9)$.

Abbreviations: $\mathrm{k}$ corresponds to the number of available trials for the outcome of interest. $\beta$ corresponds to the coefficient of meta-regression for each continuous variable tested. NP: not performed. 


\section{Supplementary material}

\section{Figure S1}

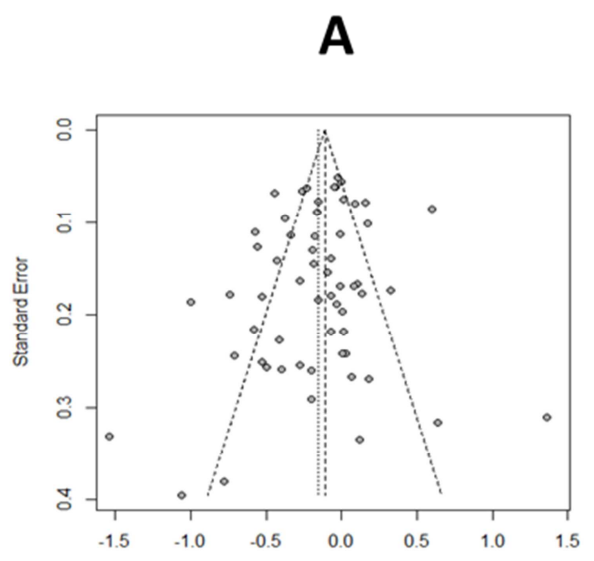

$\mathrm{FEV}_{1}$ SMD

\section{C}

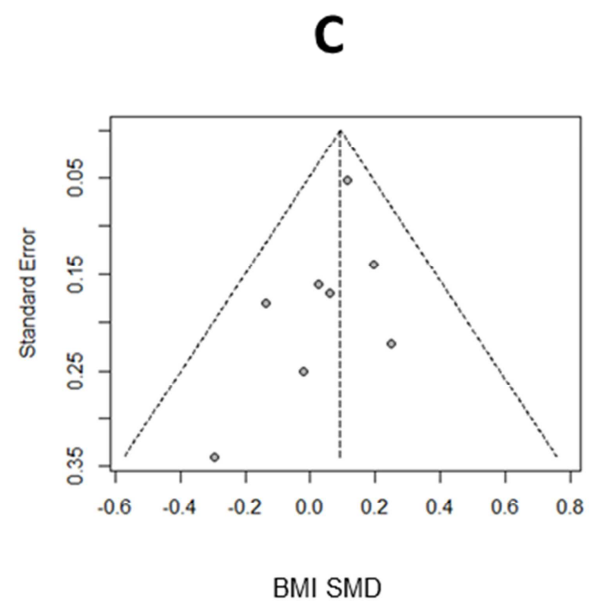

B

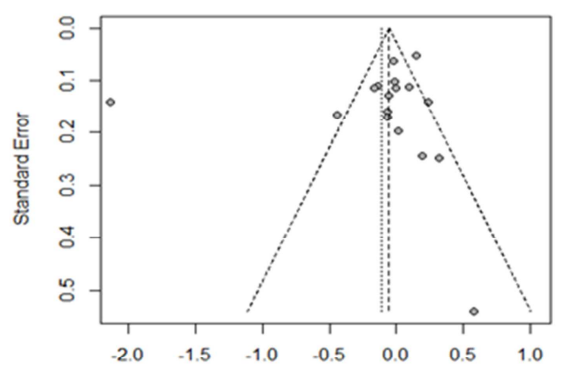

CFQR SMD

Funnel plot of standardised mean difference (SMD) for FEV 1 (A), CFQR-RD (B) and BMI (C). Funnel plots were not asymmetrical, indicating no publication bias. 


\begin{tabular}{|c|c|c|c|c|c|c|c|c|}
\hline First author & $\begin{array}{c}\text { Year of } \\
\text { publication }\end{array}$ & Investigational drug & $\begin{array}{c}\text { Drug } \\
\text { classification }\end{array}$ & Patients (n) & Male (n) & $\begin{array}{c}\text { Patient } \\
\text { age } \\
\text { ranges }\end{array}$ & $\begin{array}{l}\text { Study } \\
\text { design }\end{array}$ & $\begin{array}{c}\text { Trial } \\
\text { duration } \\
\text { (days) }\end{array}$ \\
\hline Aaron & 2012 & Itraconazol & Microbiology & 17 & 9 & $\mathrm{Ch} / \mathrm{Ad}$ & Parallel & 168 \\
\hline Accurso & 2010 & Ivacaftor & Basic Defect & 4 & 3 & $\mathrm{Ch} / \mathrm{Ad}$ & Parallel & 28 \\
\hline Accurso & 2011 & Denufosol & Pulmonary & 174 & 85 & $\mathrm{Ch} / \mathrm{Ad}$ & Parallel & 168 \\
\hline Alton & 2015 & pGM169/GL67A & Basic defect & 54 & 29 & $\mathrm{Ch} / \mathrm{Ad}$ & Parallel & 365 \\
\hline Bisgaard & 1997 & Budesonide & Pulmonary & 25 & NS & $\mathrm{Ch} / \mathrm{Ad}$ & Parallel & 91.25 \\
\hline Bowler & 1995 & Amiloride & Other & 14 & 5 & $\mathrm{Ch} / \mathrm{Ad}$ & Parallel & 15 \\
\hline Bowman & 2002 & Tobramycin & Microbiology & 262 & 132 & $\mathrm{Ch} / \mathrm{Ad}$ & Parallel & 140 \\
\hline Bradley & 2014 & Tiotropium & Pulmonary & 168 & 96 & $\mathrm{Ch} / \mathrm{Ad}$ & Parallel & 84 \\
\hline Clancy & 2013 & Arikace & Microbiology & 36 & 16 & $\mathrm{Ch} / \mathrm{Ad}$ & Parallel & 28 \\
\hline Clancy & 2012 & Lumacaftor & Basic defect & 17 & 11 & Ad & Parallel & 28 \\
\hline Clement & 2006 & Azithromycin & Pulmonary & 42 & 22 & $\mathrm{Ch}$ & Parallel & 365 \\
\hline Davies & 2013 & Ivacaftor & Basic defect & 26 & 16 & $\mathrm{Ch}$ & Parallel & 168 \\
\hline De Boeck & 2007 & Fluticasone & Pulmonary & 15 & 9 & $\mathrm{Ch}$ & Parallel & 365 \\
\hline De Boeck & 2014 & Ivacaftor & Basic defect & 39 & 22 & $\mathrm{Ch} / \mathrm{Ad}$ & $\begin{array}{c}\text { Cross- } \\
\text { over }\end{array}$ & 56 \\
\hline Deterding & 2007 & Denufosol & Pulmonary & 21 & 15 & $\mathrm{Ch} / \mathrm{Ad}$ & Parallel & 28 \\
\hline Donaldson & 2013 & Hypertonic saline & Pulmonary & 9 & 5 & $\mathrm{Ch}$ & Parallel & 28 \\
\hline Dovey & 2007 & Prednisone & Pulmonary & 12 & 9 & $\mathrm{Ch} / \mathrm{Ad}$ & Parallel & 28 \\
\hline Eigen & 1995 & Prednisone & Pulmonary & 95 & 47 & $\mathrm{Ch}$ & Parallel & 1460 \\
\hline Flume & 2012 & Ivacaftor & Basic defect & 28 & 16 & $\mathrm{Ch} / \mathrm{Ad}$ & Parallel & 112 \\
\hline Fuchs & 1994 & hrDNAse & Pulmonary & 325 & 168 & $\mathrm{Ch} / \mathrm{Ad}$ & Parallel & 168 \\
\hline Galeva & 2013 & Tobramycin & Microbiology & 32 & 13 & $\mathrm{Ch} / \mathrm{Ad}$ & Parallel & 29 \\
\hline Greally & 1994 & Prednisolone & Pulmonary & 12 & 6 & $\mathrm{Ch}$ & Parallel & 84 \\
\hline Jensen & 1987 & Colistine & Microbiology & 20 & 11 & $\mathrm{Ch} / \mathrm{Ad}$ & Parallel & 90 \\
\hline
\end{tabular}




\begin{tabular}{|c|c|c|c|c|c|c|c|c|}
\hline First author & $\begin{array}{c}\text { Year of } \\
\text { publication }\end{array}$ & Investigational drug & $\begin{array}{c}\text { Drug } \\
\text { classification }\end{array}$ & Patients (n) & Male (n) & $\begin{array}{l}\text { Patient } \\
\text { age } \\
\text { ranges }\end{array}$ & $\begin{array}{l}\text { Study } \\
\text { design }\end{array}$ & $\begin{array}{c}\text { Trial } \\
\text { duration } \\
\text { (days) }\end{array}$ \\
\hline Kerem & 2014 & Ataluren & Basic defect & 116 & 58 & $\mathrm{Ch} / \mathrm{Ad}$ & Parallel & 336 \\
\hline Konstan & 1995 & Ibuprofen & Pulmonary & 43 & 24 & $\mathrm{Ch} / \mathrm{Ad}$ & Parallel & 365 \\
\hline Lands & 2007 & Ibuprofen & Pulmonary & 72 & NS & $\mathrm{Ch}$ & Parallel & 365 \\
\hline Laube & 1996 & hrDNAse & Pulmonary & 10 & 3 & Ad & Parallel & 6 \\
\hline Mc Coy & 2008 & Aztreonam & Microbiology & 76 & 45 & $\mathrm{Ch} / \mathrm{Ad}$ & Parallel & 28 \\
\hline Mc Coy & 1996 & hrDNAse & Pulmonary & 162 & 82 & $\mathrm{Ch} / \mathrm{Ad}$ & Parallel & 91.25 \\
\hline Moran & 2009 & Repaglinide & Nutrition & 16 & 8 & Ad & Parallel & 365 \\
\hline Moran & 2009 & Repaglinide & Nutrition & 9 & 7 & Ad & Parallel & 365 \\
\hline Moss & 2015 & Ivacaftor & Basic defect & 35 & 15 & $\mathrm{Ch} / \mathrm{Ad}$ & Parallel & 168 \\
\hline Moss & 2005 & IFNgamma & Other & 21 & 9 & $\mathrm{Ch} / \mathrm{Ad}$ & Parallel & 84 \\
\hline Nahrlich & 2013 & Amitriptylin & Other & 18 & 8 & $\mathrm{Ch} / \mathrm{Ad}$ & Parallel & 28 \\
\hline Quan & 2001 & hrDNAse & Pulmonary & 235 & 121 & $\mathrm{Ch}$ & Parallel & 672 \\
\hline Ramsey & 1999 & Tobramycin & Microbiology & 262 & 132 & $\mathrm{Ch} / \mathrm{Ad}$ & Parallel & 140 \\
\hline Ramsey & 1993 & Tobramycin & Microbiology & 35 & 16 & $\mathrm{Ch} / \mathrm{Ad}$ & $\begin{array}{l}\text { Cross- } \\
\text { over }\end{array}$ & 28 \\
\hline Ramsey & 2011 & Ivacaftor & Basic defect & 78 & 38 & $\mathrm{Ch} / \mathrm{Ad}$ & Parallel & 168 \\
\hline Ramsey & 1993 & hrDNAse & Pulmonary & 48 & 26 & $\mathrm{Ch} / \mathrm{Ad}$ & Parallel & 42 \\
\hline Ranasinha & 1993 & hrDNAse & Pulmonary & 35 & 20 & Ad & Parallel & 10 \\
\hline Ratjen & 2015 & Tiotropium & Pulmonary & 155 & 90 & $\mathrm{Ch} / \mathrm{Ad}$ & Parallel & 84 \\
\hline Ratjen & 2012 & Denufosol & Pulmonary & 233 & 126 & $\mathrm{Ch} / \mathrm{Ad}$ & Parallel & 336 \\
\hline Retsch-Bogart & 2009 & AZLI & Microbiology & 84 & 45 & $\mathrm{Ch} / \mathrm{Ad}$ & Parallel & 28 \\
\hline Robinson & 2005 & hrDNAse & Pulmonary & 14 & 8 & $\mathrm{Ch}$ & Parallel & 91.25 \\
\hline Rosenfeld & 2012 & Hypertonic saline & Pulmonary & 163 & 92 & $\mathrm{Ch}$ & Parallel & 1460 \\
\hline Rowe & 2017 & Ivacaftor-Lumacaftor & Basic defect & 63 & 32 & Ad & Parallel & 56 \\
\hline Saiman & 2010 & Azithromycin & Pulmonary & 129 & 70 & $\mathrm{Ch}$ & Parallel & 168 \\
\hline Saiman & 2003 & Azithromycin & Pulmonary & 98 & 52 & $\mathrm{Ch} / \mathrm{Ad}$ & Parallel & 168 \\
\hline
\end{tabular}




\begin{tabular}{|c|c|c|c|c|c|c|c|c|}
\hline First author & $\begin{array}{c}\text { Year of } \\
\text { publication }\end{array}$ & Investigational drug & $\begin{array}{c}\text { Drug } \\
\text { classification }\end{array}$ & Patients (n) & Male (n) & $\begin{array}{c}\text { Patient } \\
\text { age } \\
\text { ranges }\end{array}$ & $\begin{array}{l}\text { Study } \\
\text { design }\end{array}$ & $\begin{array}{c}\text { Trial } \\
\text { duration } \\
\text { (days) }\end{array}$ \\
\hline Schnabel & 2007 & Somatotropin & Nutrition & 21 & NS & $\mathrm{Ch}$ & Parallel & 168 \\
\hline Serisier & 2007 & Albuterol & Pulmonary & 20 & 9 & Ad & $\begin{array}{l}\text { Cross- } \\
\text { over }\end{array}$ & 0.29 \\
\hline Shah & 1995 & hrDNAse & Pulmonary & 35 & 16 & $\mathrm{Ch} / \mathrm{Ad}$ & Parallel & 15 \\
\hline Shah & 1996 & hrDNAse & Pulmonary & 21 & NS & $\mathrm{Ch} / \mathrm{Ad}$ & Parallel & 15 \\
\hline Sheldon & 1993 & Ciprofloxacin & Microbiology & 16 & 10 & Ad & Parallel & 365 \\
\hline Steinkamp & 2008 & Azithromycin & Pulmonary & 17 & 7 & $\mathrm{Ch} / \mathrm{Ad}$ & Parallel & 56 \\
\hline Taylor-Cousar & 2017 & Tezacaftor-Ivacaftor & Basic defect & 256 & 131 & $\mathrm{Ch} / \mathrm{Ad}$ & Parallel & 168 \\
\hline $\begin{array}{l}\text { Tramper- } \\
\text { Stranders }\end{array}$ & 2010 & Colistin + Ciprofloxacin & Microbiology & 31 & 15 & $\mathrm{Ch}$ & Parallel & 1095 \\
\hline Trapnell & 2012 & Fosfomycin/Tobramycin & Microbiology & 40 & 27 & Ad & Parallel & 28 \\
\hline Tullis & 2014 & Aztreonam & Microbiology & 52 & 35 & $\mathrm{Ch} / \mathrm{Ad}$ & Parallel & 168 \\
\hline Wainwright & 2011 & Aztreonam & Microbiology & 81 & 44 & $\mathrm{Ch} / \mathrm{Ad}$ & Parallel & 28 \\
\hline Wainwright & 2015 & Lumacaftor/ivacaftor & Basic defect & 371 & 187 & $\mathrm{Ch} / \mathrm{Ad}$ & Parallel & 168 \\
\hline Wolter & 2002 & Azithromycin & Pulmonary & 30 & 20 & Ad & Parallel & 91.25 \\
\hline
\end{tabular}

Descriptive features of the studies included in the placebo-controlled trials of the meta-analysis. Ch: children; Ad: adult; IFN: interferon;

hrDNAse: human recombinant DNAse; pGM169/GL67A: name of the liposomal vector 